\title{
A Simple and Cheap Hospitalization Risk Assessment Tool for Use in Hemodialysis Patients
}

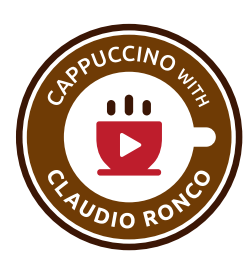

\author{
Muhammad Nauman Hashmi ${ }^{a}$ Hammad Raza ${ }^{a}$ Wael Elshazly ${ }^{a}$ \\ Fayez Hejaili $^{a, b}$ Abdullah Al Sayyari ${ }^{b}$ \\ ${ }^{a}$ King Abdullah Hemodialysis South Centre, Riyadh, Saudi Arabia; ${ }^{b}$ King Saud Bin Abdul-Aziz University \\ for Health Sciences, Riyadh, Saudi Arabia
}

\section{Keywords}

Mortality · Hospitalizations · Hemodialysis · Assessment tool

\begin{abstract}
Objective: To develop a simple, objective, cheap scoring tool incorporating nutritional parameters and other variables to predict hospitalization and mortality among hemodialysis patients - a tool that could be utilized in low resource countries. Methods: The following variables were scored according to severity into $0,1,2$ or 3: BMI, functional capacity, $H D$ vintage in years, serum albumin, serum ferritin, and the number of comorbid conditions (diabetes mellitus, hypertension, ischemic heart disease, cerebrovascular disease). This tool was evaluated on our regular hemodialysis patients who were followed up for 24 months (June 2015 till July 2017). In our study population, the maximum score recorded was 12; accordingly, a score of 6 was used to differentiate between a low-risk group (score $<6$ ) or a high-risk group (score $\geq 6$ ). The 2 groups were compared (using the Chi square test) for possible differences in mortality and hospitalization rates during the follow-up period. Results: One hundred and forty adult hemodialysis patients were monitored over 2 years; 83 were males and 57 females; $59 \%$ of the
\end{abstract}

patients had diabetes mellitus. Twenty-nine patients (30.7\%) were found to be in the high-risk group and 111 (79.3\%) in the low-risk group. The high-risk patients were almost one and a half times more likely to be hospitalized for vascular access issues than the low-risk group $(p=0.056)$ and 3 times more likely to be hospitalized for non-vascular access issues than the low-risk group $(p=0.0001)$. The mortality rate in the high-risk group was 3.1 times that in the low-risk group, but this was not statistically significant. Conclusion: Using a simple and cheap assessment tool in hemodialysis patients, we have identified patients at high risk for hospitalization rates and mortality. Video Journal Club "Cappuccino with Claudio Ronco" at http://www.karger.com/?doi=490544.

(c) 2018 S. Karger AG, Basel

\section{Introduction}

Protein energy malnutrition (PEM) is a common problem in chronic kidney disease (CKD) patients and is often difficult to assess $[1,2]$. It is a risk factor for mortality and morbidity $[3,4]$. In the last decade, nutritional scoring systems have been developed and recommended

\section{KARGER}

(c) 2018 S. Karger AG, Basel

E-Mail karger@karger.com

www.karger.com/bpu
Dr. Muhammad Nauman Hashmi

King Abdullah Hemodialysis South Centre Riyadh (Saudi Arabia)

E-Mailmnhaxmi@hotmail.com 
Table 1. Scoring tool

\begin{tabular}{lllll}
\hline & 0 & 1 & 2 & 3 \\
\hline BMI & $\geq 20$ & $18-19.99$ & $16-17.99$ & $<16$ \\
Functional capacity & Normal & $\begin{array}{c}\text { Occasional difficulty in } \\
\text { daily activities }\end{array}$ & $\begin{array}{c}\text { Difficulty in independent } \\
\text { activities }\end{array}$ & Bed/chair ridden \\
Number of years on HD & $<1$ year & $1-<3$ years & $3-4$ years & $>4$ years \\
Serum albumin & $\geq 35 \mathrm{~g} / \mathrm{L}$ & $32-35 \mathrm{~g} / \mathrm{L}$ & $28-31 \mathrm{~g} / \mathrm{L}$ & $<28 \mathrm{~g} / \mathrm{L}$ \\
Serum ferritin & $<700 \mu \mathrm{g} / \mathrm{L}$ & $700-800 \mu \mathrm{g} / \mathrm{L}$ & $300-1,000 \mu \mathrm{g} / \mathrm{L}$ & $>1,000 \mu \mathrm{g} / \mathrm{L}$ \\
Comorbidities & 1 & 2 & 3 & $>3$
\end{tabular}

Comorbidities $=$ diabetes mellitus, hypertension, ischemic heart disease, cerebrovascular disease.

as practical tools for the diagnosis of malnutrition in endstage renal failure patients [5].

Protein energy wasting is defined by low serum albumin, low body mass index, and reduced muscle mass (sarcopenia) [5].

CKD leads to multiple events that cause PEM and that can eventually lead to increased morbidity and mortality. These include dialysis-associated catabolism, metabolic abnormalities, uremic toxins, reduced dietary intake, and chronic inflammatory state [6].

Several parameters have been used in order to determine protein energy wasting. Serum albumin, low body mass index, inflammatory markers (IL-6, CRP), muscle mass assessment, and dietary assessment have been commonly used in the evaluation of protein energy wasting in renal failure patients [7-12]. Current tools to assess nutritional status in renal failure patients are based on a combination of these parameters [13-15].

The existing scoring systems are subjective global assessment of nutritional status or some modified versions $[16,17]$. There is no unified agreement on these scoring systems and how accurately they correlate with PEM [5].

Many dialysis units have limited resources in which many of the above tools are not available. Moreover, many current scoring tools are subjective and the cost is a limiting factor in objective assessments. Our aim is to develop a simple, objective, cheap scoring tool incorporating nutritional parameters and other variables to predict hospitalization and mortality among hemodialysis patients and that which could be utilized in low resource settings.

\section{Methods}

The following variables were scored according to severity as 0 , 1,2 , or 3: BMI, functional capacity, hemodialysis (HD) vintage in years, serum albumin, serum ferritin and the number of coexisting comorbid conditions (diabetes mellitus, hypertension, ischemic heart disease, cerebrovascular disease; Table 1).

Difficulty in independent activity was defined as either selfreported or family-reported inability to perform expected daily activities such as personal hygiene, using the toilet independently, dressing oneself and eating unaided.

Occasional difficulty in daily activities is defined as self-reported or family-reported similar events but occurring less than 3 times per week.

We evaluated this tool on all of our regular chronic hemodialysis patients over a period of 24 months (June 2015 till July 2017). Based on the results of the scoring system, the patients were categorized into either a low-risk group (score $<6$ ) or a high-risk group (score $\geq 6$ ). The 2 groups were then compared (using the Chi square test) in terms of mortality rate, hospitalization rate for vascular access issues, for other issues and total hospitalization rates during the follow-up period.

This study was performed after obtaining informed verbal consent from patients and no further ethical permissions by committees were required/necessary.

\section{Results}

The tool was used in 140 adult hemodialysis patients who were monitored over 2 years; 83 were males and 57 females; $59 \%$ of the patients had diabetes mellitus. (Table 2); $22.9 \%$ of the patients included were smokers.

Twenty-nine patients (30.7\%) were categorized as being in the "high-risk" group and $111(79.3 \%)$ as being in the "low-risk" group (Table 3).

The high-risk patients were almost one and a half times more likely to be hospitalized for vascular access issues than the low-risk group $(p=0.056)$ and 3 times more likely to be hospitalized for non-vascular access issues than the low-risk group ( $p=0.0001$; Fig. 1 ). The mortality rate was 3.1 times higher, but this does not reach statistical significance $(p=0.1112)$. 
Table 2. Demographic and clinical data

\begin{tabular}{lcc}
\hline Characteristics & Number of patients & Percentage \\
\hline Gender & & 59 \\
$\quad$ Male & 83 & 41 \\
Female & 57 & 5 \\
Body mass index & 7 & 64 \\
$\quad<18$ & 90 & 31 \\
18-30 & 43 & 59 \\
$>30$ & & 41 \\
Diabetic status & 83 & 10 \\
Diabetes mellitus & 57 & 84 \\
Non diabetic & 14 & 6 \\
Marital status & 118 & 85.8 \\
Single & 8 & 23.6 \\
Married & 120 & 89.3 \\
Divorced/widowed & 33 & $5.4 \pm 5.3$ \\
Patients with hypertension & 110 & $1.6 \pm 0.4$ \\
$\quad$ Patients with history of IHD & 135 & $11.4 \pm 1.4$ \\
Patients on Epo & 140 & $36.4 \pm 4.5$ \\
Number of years on dialysis, years, mean \pm SD & 140 & \\
Kt/V, mean \pm SD & 140 & \\
Baseline hemoglobin, gm/L, mean \pm SD & & \\
Serum albumin, gm/L, mean \pm SD & & \\
\hline
\end{tabular}

IHD, ischaemic heart disease.

Table 3. Hospitalization and mortality rates among the high- and low-risk groups over the observation period

\begin{tabular}{llll}
\hline & $\begin{array}{l}\text { High risk group } \\
(n=29)\end{array}$ & $\begin{array}{l}\text { Low risk group } \\
(n=111)\end{array}$ & OR value \\
\hline Total hospitalization rate/person in the group & 1.2 & 0.9 & 1.5 \\
Hospitalization rate for non-vascular access/person in the group & 6.2 & 2.0 & 0.054 \\
Hospitalization rate for other causes/person in the group & 7.4 & 2.9 & 0.0001 \\
Mortality rate during the observation period, \% & 13 & 4.5 & 0.0001 \\
\hline
\end{tabular}

\section{Discussion}

PEM is common in CKD and is associated with adverse clinical outcomes, especially in individuals receiving maintenance dialysis therapy. Multiple studies indicate increased rates of hospitalization and death in malnourished patients [1].

In recent years, nutritional scoring systems have been recommended as practical tools for diagnosis of malnutrition in individuals with kidney disease $[13,14]$.

We propose a more objective assessment tool in order to assess malnourished hemodialysis patients. Our aim was to design a comprehensive scoring system that is easily applied and reproducible and helps to identify patients at risk of PEM.

Predictive Tool for of Mortality and Hospitalization in Hemodialysis patients
We developed a nutritional assessment tool based on body mass index, functional capacity, HD vintage in years, serum albumin, serum ferritin, and comorbid conditions (diabetes mellitus, hypertension, ischemic heart disease, cerebrovascular disease). These variables were given a score of $0,1,2$ or 3 according to their severity. Over a 2-year period (June 2015 till July 2017), we followed 140 regular hemodialysis patient who attended our center for chronic hemodialysis. This assessment tool was applied quarterly and the patient's score was recorded. During this study period, the maximum recorded score was 12 in our studied population (maximum possible score 18). Based on our maximum recorded score of 12 , we considered a cutoff point of score 6 to classify patients into 2 groups (high-risk score $\geq 6$ and low-risk score $<6$ ). 


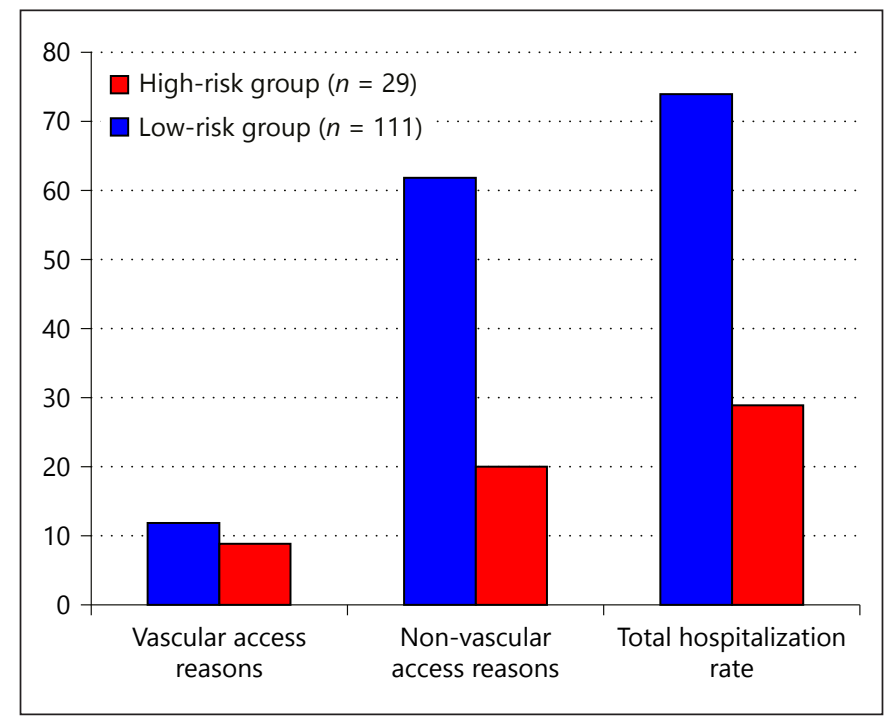

Fig. 1. Hospitalization rate in the high- and low-risk groups.

In the low-risk group (score $<6$ ), there were 111 patients and in the high-risk group (score $\geq 6$ ), there were 29 patients.

We analyzed the data at the end of 24 months and observed a mortality rate of $4.5 \%$ in the low-risk group and
$13 \%$ in the high-risk group and the hospitalization rate was significantly higher in the high-risk group during this study period.

The 2 groups were compared using Chi-square test in terms of mortality and hospitalization rate (vascular access related and non-vascular related). The high-risk group was 1.5 times more likely to be hospitalized for vascular issues as compared to the low-risk group $(p=0.056)$ and 3 times more likely to be hospitalized for non-vascular issues than the lower risk group ( $p=0.0001)$. The mortality rate is 3.1 times, but does not reach statistical significance $(p=0.1112)$.

Using this simple tool, we have identified patients at risk for hospitalization. This helps in focusing care in such patients by reviewing and involving dietitian support and family education in order to minimize their risk.

Due to the low numbers in the study, it should be highlighted that statistical conclusions may not be robust enough and therefore, a study on a larger number of patients would be instructive.

\section{Disclosure Statement}

No conflict of interest is declared by any of the authors.

\section{References}

1 Ikizler TA, Cano NJ, Franch H, Fouque D, Himmelfarb J, Kalantar-Zadeh K, Kuhlmann MK, Stenvinkel P, TerWee P, Teta D, Wang AY, Wanner C: Prevention and treatment of protein energy wasting in chronic kidney disease patients: a consensus statement by the International Society of Renal Nutrition and Metabolism. Kidney Int 2013;84:1096-1107.

2 Segall L, Mardare NG, Ungureanu S, Busuioc M, Nistor I, Enache R, Marian S, Covic A: Nutritional status evaluation and survival in haemodialysis patients in one centre from Romania. Nephro Dial Transplant 2009;24:2536-2540.

3 Kalantar-Zadeh K, Block G, McAllister CJ, Humphreys MH, Kopple JD: Appetite and inflammation, nutrition, anemia, and clinical outcome in hemodialysis patients. Am J Clin Nutr 2004;80:299-307.

4 Clinical practice guidelines for nutrition in chronic renal failure. K/DOQI, National Kidney Foundation. Am J Kidney Dis 200;35(6 suppl 2):S1-S140.

5 Fouque D, Kalantar-Zadeh K, Kopple J, Cano N, Chauveau P, Cuppari L, Franch H, Guarnieri G, Ikizler TA, Kaysen G, Lindholm B, Massy Z, Mitch W, Pineda E, Stenvinkel P, Treviño-Becerra A, Wanner C: A proposed nomenclature and diagnostic criteria for pro- tein-energy wasting in acute and chronic kidney disease. Kidney Int 2008;73:391-398.

6 Kalantar-Zadeh K, Ikizler TA, Block G, Avram MM, Kopple JD: Malnutrition-inflammation complex syndrome in dialysis patients: causes and consequences. Am J Kidney Dis 2003;42:864-881.

7 Iseki K, Kawazoe N, Fukiyama K: Serum albu$\mathrm{min}$ is a strong predictor of death in chronic dialysis patients. Kidney Int 1993;44:115119.

8 Kaysen GA: Biological basis of hypoalbuminemia in ESRD. J Am Soc Nephrol 1998;9: 2378-2376.

9 Kalantar-Zadeh K, Kilpatrick RD, Kuwae N, McAllister CJ, Alcorn H Jr, Kopple JD, Greenland S: Revisiting mortality predictability of serum albumin in the dialysis population: time dependency, longitudinal changes and population-attributable fraction. Nephro Dial Transplant 2005;20:1880-1888.

10 Beddhu S, Kaysen GA, Yan G, Sarnak M, Agodoa L, Ornt D, Cheung AK: Association of serum albumin and atherosclerosis in chronic hemodialysis patients. Am J Kidney Dis 2002; 40:721-727.

11 Kaysen GA, Gambertoglio J, Jimenez I, Jones $\mathrm{H}$, Hutchison FN: Effect of dietary protein in- take on albumin hemostatsis in nephrotic patients. Kidney Int 1986;29:572-577.

12 Kopple JD, Mehrotra R, Suppasyndh O, Kalantar-Zadeh K: Observations with regard to the National Kidney Foundation K/DOQI clinical practice guidelines concerning serum transthyretin in chronic renal failure. Clin Chem Lab Med 2002;40:1308-1312.

13 Bologa RM, Levine DM, Parker TS, Cheigh JS, Serur D, Stenzel KH, Rubin AL: Interleukin-6 predicts hypoalbuminemia, hypocholesterolemia, and mortality in hemodialysis patients. Am J Kidney Dis 1998;32:107-114.

14 Chertow GM, Ackert K, Lew NL, Lazarus JM, Lowrie EG: Prealbumin is as important as albumin in the nutritional assessment of hemodialysis patients. Kidney Int 2000;58:2512-2517.

15 Cano NJ: Metabolism and clinical interest of serum transthyretin (prealbumin) in dialysis patients. Clin Chem Lab Med 2002;40:1313-1319.

16 Steiber AL, Kalantar-Zadeh K, Secker D, McCarthy M, Sehgal A, McCann L: Subjective global assessment in chronic kidney disease: a review. J ren Nutr 2004;14:191-200.

17 Fouque D, Vennegoor M,Wee P, Wanner C,Basci A, Canaud B, Haage P et al: EPBG guideline on nutrition. Nephro Dial Transplant 2007;22:ii45-ii87. 